\title{
DOES THE LEVEL OF POLITENESS USED BY A SOCIAL ROBOT AFFECT CHILDREN'S LEARNING?
}

\author{
Hsiu-Feng Wang \\ National Chiayi University, Taiwan
}

\begin{abstract}
This study examined the impact of social robot's politeness strategy on the learning outcome and interest of children. The experimental study employed a within-subject design to investigate the effect of social robot's politeness strategy. The dependent variables are children's learning outcomes and learning interests. A total of 40 participants were involved. Participants' learning interests are measured by the Study Interest Questionnaire (SIQ), which included three aspects: feeling, value, and intrinsic. The results showed that there was no significant difference between children's learning outcomes and the level of politeness with social robots. However, in terms of learning interest, a higher level of polite feedback may be more beneficial to children. The findings of this experiment should be of value to people involved in the design of children's learning material with the social robots and those who work on interaction design with children.
\end{abstract}

\section{KEYWORDS}

Politeness Theory, Children, Social Robot, Learning Outcome, Learning Interest

\section{INTRODUCTION}

Many educators and parents believe that social robots create engaging learning experiences for children. Indeed, social robots are often bought by schools and families to teach younger ones' mathematics, new words and so on. However, despite their growing popularity, there is still limited understanding as to how social robots should interact in order to foster effective learning in children. This study investigates the impact of different level of politeness with social robot's feedback on children's learning outcome and interest.

\section{BACKGROUND OF THE STUDY}

Brown and Levinson (1987) devised a prominent approach called politeness theory to examine people's communication. According to politeness theory, everybody has a positive and negative "face" cross-culturally. The concept originates from Goffman (1967) described as a constructed self-image. The idea of negative face means that people do not want others to disrupt with their affairs because they do not want to lose their autonomy. The idea of positive face means that people desire others to be appreciated and approved of them. There are some communication acts such as requests or too direct can threaten the people's negative face, they referred to as face threatening acts (FTAs). For example, in this experiment, the direct wording of feedback (such as "It's so easy, everyone should know it.") from social robot can threaten student's negative face and restricting their willingness to work cooperatively with the social robot.

A number of researches based on theories of politeness investigations have since been conducted, seeking to understand the politeness effect in more detail. Ginns et al. (2013) reviewed a meta-analysis showed that politeness could enhance learning outcome. They revealed that the possible explanations are that politeness can act as social cues, may increase the perception of a system's (such as: intelligent tutors or social robot) friendliness therefore, enhance learners' effective processing. Another empirical research has similar results. Wang et al. (2008) conducted an experiment, they asked college students to learn to play an industrial engineering game named Virtual Factory. In the game, students learn how to assemble line processes 
efficiently by online tutor. They found that students who received polite feedback from an online tutor learned more than those who received direct (impolite) feedback; however, there were no statistically reliable differences between conditions on ratings of self-efficacy and interest. Wang and Johnson (2008) also found a politeness effect in a web-based tutoring system for teaching foreign language, with adults who were unfamiliar with the cultural context of the language. However, Other studies of politeness effects have found mixed results. A recent study conducted by Mikheeva et al. (2019), they recruited 277 students learned mathematics in a web-based intelligent tutor. The tutor provided either polite or direct instructions and feedback to students. The results showed that politeness in feedback influenced learning positively, but politeness in instructions did not have any influence.

The above paragraphs illustrate that there is a lack of consistency in the literature with respect to results that relate to politeness: some experiments support politeness theory while others do not. This suggests that more research is needed in this area. It is hypothesized that: Does social robot's feedback with different levels of politeness affect learning outcomes and interest in children?

\section{METHOD}

\subsection{Participants and Design}

Forty Taiwanese primary school children participated in the experiment. The children came from the same rural primary school in Chiayi, Taiwan. The mean age was 11.4 years $(S D=.47)$; it comprised 21 boys and 19 girls. All the children attended computer lessons at least twice a week, played computer game and used the Internet. All had passed the school's internal Chinese language examination. The experiment used a within-subject design to discover how different level of politeness of feedback on the social robots affected children's learning outcome and learning interest. The independent variable was the difference level of politeness. The three levels were: high, medium and low politeness. The experiment had two dependent variables: children's learning outcome and learning interest.

\subsection{Materials}

The experiment uses NUWA Robotic manufactured Kebbi social robots which specifically designed for children. The Kebbi social robots were used for children to watch video (use animation as teaching material) and to conduct the interactive test during this experiment. The narration and feedback was done by a 20 -year-old male professional voice. The robot gives facial expression from its build-in databank when giving feedback to match the voice tone.

Table 1. Feedback given in different levels of politeness

\begin{tabular}{|l|l|l|l|}
\hline $\begin{array}{l}\text { Feedback/Level of } \\
\text { politeness }\end{array}$ & High level of politeness & Medium level of politeness & Low level of politeness \\
\hline $\begin{array}{l}\text { Correct feedback } \\
\text { (Positive feedback) }\end{array}$ & Wow! You are awesome. & It's correct. & $\begin{array}{l}\text { It's so easy, everyone should } \\
\text { know it! }\end{array}$ \\
\hline $\begin{array}{l}\text { Incorrect feedback } \\
\text { (Negative feedback) }\end{array}$ & Think again. & It's incorrect. & $\begin{array}{l}\text { Everyone knows it, and you } \\
\text { didn't know! }\end{array}$ \\
\hline
\end{tabular}

The video and test questions uses in experiment were designed by three specialists (including two school teachers who had over 7 years of teaching experience and one interaction designer with over 10 years of working experience). They created a set of teaching materials in the form of animation that suifigure for age 11-12 children. The three specialists eventually decided to use the theme "Life of a classical musician" for the content for this experiment. The video is in three parts, after playing each part of video, participants need to touch the social robot monitor to answer 4 questions related the content in the video, and once the answers were given, robot will randomly give feedback from 3 different levels of politeness. For example, when first part of video gives feedback from high level of politeness, the social robot will reply "Wow! You are awesome" (see Table 1 ), and show a smiling face (see Figure 1a). On the other hand, when answering incorrectly, the social robot will reply "Think again" (see Table 1), and show a sad face (see Figure 1b). The 
facial expression of social robot from different level of politeness were the same for correct answer, and incorrect answer. The verbal feedbacks were different according to the level of politeness which participants viewed. The feedback given after answering the question was designed according to Mayer et al. (2006) 's different levels of politeness.

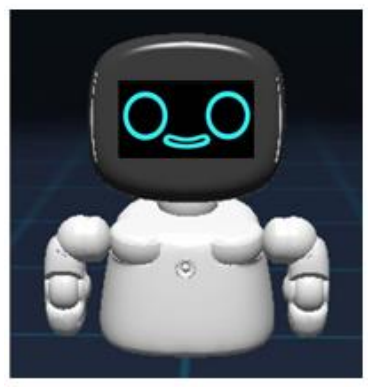

(a) Facial expression for correct answer

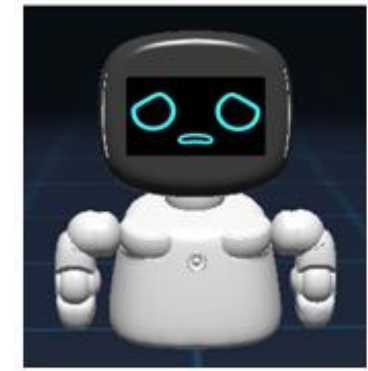

(b) Facial expression for Incorrect answer

Figure 1. Social robot facial expression used in the experiment

\subsubsection{Learning Test}

The learning test took the same set of prior-knowledge questionnaire with different questions order. And then answer the test questions on social robot right after reviewing the video. The robot will give feedback with facial and verbal expression according to the answers given by participants.

\subsection{Procedure}

On arrival at the lab, an experimenter collected participants' consent forms which had their parent/guardian signed in advance of the experiment. Each participant was given his/her own social robots and worked alone. During the experiment, one participant in the classroom at a time with an experimenter. The experimenter gave oral instructions and demonstration of how to operate the social robot. Participants have been told that they can interact with the social robot freely for three minutes to familiar with social robot. Then, each participant started with the practice trial. The practice trial involved the children viewing the video on social robot (mentioned in Section 3.2.1) and answering two multiple-choice questions about each one. The section lasted no more than 10 minutes.

The experiment involved each child viewing video on social robot. The video divided into three parts with approximately equal length, after participants viewing each part of video, four questions will appear randomly. Participants need to answer the questions by touching the robot monitor, the social robot will give feedback with different level of politeness (either high, medium or low); each part have the same level of politeness, so that each participant received equal exposed to the three levels of politeness. The children were told that they could take as long as they wanted to answer the questions and should click the 'Done' button on social robot when finished.

Once everybody had completed the activity a questionnaire was distributed. Each question was explained and the children completed the questionnaire independently. During the sessions no child showed signs of fatigue. Before leaving the room, each child filled out a demographic form and received a stationary gift.

\section{RESULTS}

A one-way ANOVA was carried out to evaluate the different levels of politeness with respect to mean scores. The means and standard deviations for the scores obtained in the tests are shown in Table 2.

No significant effect of different levels of politeness on the learning outcome scores was found, $F(2,78)$ $=0.27, p=.954$. The results revealed that there was a significant difference between children's learning interest and the different levels of politeness, $F(2,78)=11.167, p=.000$.

In terms of learning interest ratings, the highest score was given to the high level of politeness, followed by the medium level of politeness, then the low level of politeness. Further multiple comparisons using the Scheffé statistical test showed that the difference between the high level of politeness was significantly 
higher than the low level of politeness $(p=.000)$; and that the medium level of politeness was significantly higher than the low level of politeness $(p=.005)$. A significant difference was also found between the learning interest ratings for the high level of politeness and medium level of politeness $(p=.019)$.

Table 2. Descriptive statistics for learning outcome and learning interest

\begin{tabular}{lll}
\hline & $M$ & $S D$ \\
\hline Learning outcome & & \\
High & 1.50 & 1.02 \\
Medium & 1.47 & .904 \\
Low & 1.45 & 1.05 \\
Learning interest & & \\
High & 3.89 & .675 \\
Medium & 3.72 & .734 \\
Low & 2.49 & .812 \\
\hline
\end{tabular}

\section{CONCLUSION}

The experiment examined the politeness strategy on social robot with respect to children's learning interest and learning interest. It tested politeness theory of people's communication which claims that people prefer positive face than negative face. We divided the politeness according its directness into three levels (high, medium, low) on the feedback given by social robot.

The results showed that there was no significant difference between children's learning outcome and the level of politeness with social robot. However, it also showed that politeness had an impact on learning interest: children preferred high levels of politeness. This was in line with politeness theory. These results are comparable to those obtained by Mikheeva et al. (2019) and Wang and Johnson (2008), found that politeness in feedback influenced learning positively. This experiment clearly identified that different levels of politeness significantly impact on children's learning interests, but not learning outcome. This research should be useful to educators, instructional designers and social robot developers who create teaching materials for children. Further research is needed to determine how politeness strategy affects children' learning, when different age's children interactive with social robot.

\section{ACKNOWLEDGEMENT}

This experiment was kindly supported by a grant from the National Science Council of Taiwan. (Contract number: NSC109-2410-H-415-004).

\section{REFERENCES}

Brown, P., \& Levinson, S. C. (1987). Politeness: Some universals in language usage. Cambridge university press.

Ginns, P., \& Martin, A. J. \& Marsh, H. W. (2013). Designing Instructional Text in a Conversational Style: A Meta-analysis, Educational Psychology Review, 25(4), 445-472.

Goffman, E. (1967). On facework. In E. Goffman (Ed.). Interaction ritual (pp. 5-45). New York: Doubleday Anchor.

Mikheeva, M., Schneider, S., Beege, M., \& Rey, G. D. (2019). Boundary conditions of the politeness effect in online mathematical learning, Computers in Human Behavior, 92, 419-427.

Mayer, R. E., Johnson, W. L., Shaw, E., \& Sandhu, S. (2006). Constructing computer-based tutors that are socially sensitive: Politeness in educational software, International Journal of Human-Computer Studies, 64, 36-42.

Wang N., \& Johnson W.L. (2008). The Politeness Effect in an Intelligent Foreign Language Tutoring System. In: Woolf B.P., Aïmeur E., Nkambou R., Lajoie S. (eds) Intelligent Tutoring Systems. ITS 2008. Lecture Notes in Computer Science, vol. 5091. Springer, Berlin, Heidelberg.

Wang, N., Johnson, W. L., Mayer, R. E., Rizzo, P., Shaw, E., \& Collins, H. (2008). The politeness effect: Pedagogical agents and learning outcomes. International Journal of Human-computer Studies, 66, 98-112. 